\title{
Aspectos epidemiológicos da meningite no município de Porto Nacional (TO), no período de 2014 a 2018
}

A meningite é uma doença caracterizada por uma inflamação das meninges, que podem acometer tanto o segmento medular, quanto o cranial. É classificada como asséptica e bacteriana. Dentre a classificação asséptica, refere-se à meningite causada por fungos, vírus, e outras causas menos comuns. Já a bacteriana pode ser causada por várias etiologias, entre elas a meningocócica, pneumocócica, tuberculosa, entre outros. O tipo mais grave de meningite é a bacteriana, devido à alta morbidade e mortalidade. Entretanto, é uma doença com imunização. A partir disso, buscou-se a investigação dos aspectos epidemiológicos da meningite em todas as suas formas na cidade de Porto Nacional (TO), onde se identificou que os aspectos do município são semelhantes aos aspectos estaduais e nacionais, com maior prevalência em homens, na raça parda e na idade pediátrica, com exceção para os dados nacionais em que foi mais prevalente nos adultos. Um aspecto preocupante identificado no município que se difere dos dados nacionais e estaduais é a maior incidência de meningite bacteriana, mais grave que as outras formas, e, apesar de não haver uma alta incidência, tanto da bacteriana quanto das outras etiologias, deve haver uma maior atenção da saúde pública para a prevenção da meningite.

Palavras-chave: Epidemiologia; Incidência; Meningite; Porto Nacional.

\section{Epidemiological aspects of meningitis in the city of Porto Nacional (TO), from 2014 to 2018}

Meningitis is a disease characterized by inflammation of the meninges, which can affect both the medullary and the cranial segments. It is classified as aseptic and bacterial meningitis. Among the aseptic classification, meningitis caused by fungi, viruses, and other less common causes. Already bacterial can be caused by several etiologies, including meningococcal, pneumococcal, tuberculous, among others. The most serious type of meningitis is bacterial due to its high morbidity and mortality. However, it is a disease with immunization. From this, we sought to investigate the epidemiological aspects of meningitis in all its forms in the city of Porto Nacional (TO), where it was identified that the aspects of the municipality are similar to the state and national aspects, with higher prevalence in men. mixed race and pediatric age, except for national data where it was more prevalent in adults. A worrying aspect identified in the municipality that differs from national and state data is the higher incidence of bacterial meningitis, more severe than other forms, and although there is no high incidence of both bacterial and other etiologies, there must be a higher incidence of bacterial meningitis. greater public health attention to the prevention of meningitis.

Keywords: Epidemiology; Incidence; Meningitis; National Port.

\section{Topic: Epidemiologia}

Reviewed anonymously in the process of blind peer.
Received: 15/03/2019

Approved: 17/05/2019
Vinicius Pereira Colman

Instituto Tocantinense Presidente Antônio Carlos, Brasil http://lattes.cnpq.br/2594509327462075

viniciuspereiracolman@hotmail.com

\section{Nasser Reda}

Instituto Tocantinense Presidente Antônio Carlos, Brasil http://lattes.cnpq.br/4943292173588322

nasserre@hotmail.com
Referencing this:

COLMAN, V. P.; REDA, N.. Aspectos epidemiológicos da meningite no município de Porto Nacional (TO), no período de 2014 a 2018. Scire Salutis, v.9, n.2, p.49-59, 2019. DOI:

http://doi.org/10.6008/CBPC2236-9600.2019.002.0006 


\section{INTRODUÇÃO}

Segundo Guimarães et al. (2010), as doenças infecciosas são de grande representatividade em todo o mundo, onde se caracterizam como a segunda maior causa de mortalidade. Pereira (2014) afirma que as doenças infecciosas atingem de forma letal principalmente a população infantil, e entre as principais doenças há um destaque para a meningite. De acordo com Fernandes et al. (2008), as meningites podem acometer as meninges e o espaço subaracnóideo por continguidade ou via hemorrágica, e se associam ao morbimortalidade significativa, onde devido a gravidade clínica há uma importância do reconhecimento precoce.

No passado, a maioria dos casos de meningite levava ao óbito ou deixavam sérias sequelas neurológicas nos pacientes sobreviventes. Entretanto, isso mudou a partir do conhecimento profundo da patologia, com o desenvolvimento de vacinas e antibióticos, diminuindo os casos de morte e promovendo saúde e qualidade de vida (SANTOS, 2007).

Segundo Cordeiro (2013), a meningite é uma doença que se caracteriza pela inflamação das finas membranas, a dura mater, a aracnoide e a pia mater, onde estas circundam o cérebro e a medula espinhal, podendo ser classificada como asséptica ou bacteriana. Cordeiro (2013) afirma que a meningite asséptica pode ser causada por fungos, vírus, agentes químicos ou por desordens do tecido conectivo adjacente.

As meningites causadas por fungos, ou meningites fungicidas, podem partir de infecções ou surgir em hospedeiros imunocomprometidos, como pessoas com diabetes, AIDS, etc., e podem causar formação de abscessos, paralisia dos nervos cranianos, arterite com infarto cerebral e hidrocelia, e possui os seguintes agentes patológicos: Cryptococcus neofarmans, Coccidioides immitis, Candida albicans, Aspergillus spp, Histoplasma capsulatum, Blatomyces e Mucor spp (DEVINSY, 2001).

A meningite causada por vírus, ou meningite viral, é mais frequente na infância e em meninos, entretanto pode acometer outras idades, com raros casos após os 40 anos, sendo que normalmente é benigna, transmitida de pessoa a pessoa, de acordo com o agente etiológico, podendo causar hipertermia, cefaleia, astenia, mialgia, rigidez da nuca, distúrbios gastrointestinais, erupção cutânea, etc. (PERES et al., 2006). A meningite viral pode ser causada por vários tipos de vírus, o principal é o enterovírus, mas também pode ser causada pelo vírus da caxumba, do herpes, da varicela, do sarampo, da rubéola, os arbovírus e os adenovírus (PERES et al., 2006).

No que se refere à meningite bacteriana BRASIL (2017), os principais agentes bacterianos que causam a meningite são: Neisseria meningitidis (meningococo), sendo que este é a principal causa da meningite bacteriana no Brasil; Streptococcus pneumoniae (pneumococo); Haemophilus influenzae; além de outras bactérias, com destaque para Mycobacterium tuberculosis; Streptococcus sp., especialmente os do grupo B; Streptococcus agalactie; Listeria monocytogenes; Staphylococcus aureus; Pseudomonas aeruginosa; Klebsiella pneumoniae; Enterobacter sp.; Salmonella sp.; Proteus sp.

Segundo Santos (2007), as meningites bacterianas são graves problemas de saúde pública, devido à alta prevalência, principalmente em crianças, à alta mortalidade e às sequelas que em muitos casos são irreversíveis, sendo que qualquer bactéria pode causar meningite, onde cada agente etiológico possui suas 
características: Meningite meningocócica: Possui alta gravidade, causa infecções endêmicas e epidêmicas em todo mundo; Meningite causada pelo Haemophilus Influenzae: Prevalente em lactentes e crianças menores de 5 anos, entretanto é uma doença comum e com poucos casos; Meningite pneumocócica: Possui alta frequência, e alta taxa de morbidade e letalidade, especialmente nos primeiros anos de vida. A letalidade pode ser reduzida com imunização.

Além dessas, Meningite estafilocócica: são raros os casos, mas podem ocorrer de patologias como furúnculos, abscesso epidural ou subdural, complicação da trombose, infecção estafilocócica ou a partir de procedimentos cirúrgicos; e Meningite tuberculosa: comum em crianças e recém-nascidos em locais com altos índices de tuberculose, possui evolução lenta.

De acordo com a Diretoria de Vigilância Epidemiológica de Santa Catarina, a meningite bacteriana merece destaque, pois, esta é a forma mais grave de meningite. Devido a gravidade da meningite em todas as suas formas, ela é definida por lei, através da Portaria no 204 de 17 de fevereiro de 2016, como uma doença de notificação compulsória, devendo ser notificada imediatamente, em até 24 horas.

Diante da gravidade e complexidade da doença, mesmo com os avanços da medicina, este trabalho objetiva a investigação dos aspectos epidemiológicos da meningite na cidade de Porto Nacional (TO), por se tratar de uma cidade por muitas vezes negligenciada pela saúde pública. Pobb (2013) afirma que a investigação da epidemiologia da meningite é fundamental para a identificação dela, bem como para a redução e prevenção desse agravo. Além disso, Pobb (2013) afirma que, quanto maior a quantidade de varáveis analisadas, mais ampla será a investigação. Desse modo, buscou-se uma ampla coleta de variáveis, de modo a ter uma maior qualificação a este estudo. A partir dos aspectos epidemiológicos, também se identificou o perfil epidemiológico das vítimas de meningite no município.

\section{METODOLOGIA}

\section{Desenho de estudo}

A pesquisa é caracterizada como do tipo descritiva, através de uma abordagem quali-quantitativa. Segundo Gil (2008), a pesquisa descritiva possui o objetivo de descrever as características de um fenômeno ou de uma população pesquisada, estudando pontos como sexo, idade, escolaridade, renda, saúde, etc.. A abordagem quali-quantitativa é uma junção das abordagens qualitativa e quantitativa. De acordo com Gerhardt et al. (2009), essa junção é fundamental para um maior desenvolvimento de uma pesquisa, visto que uma abordagem complementa a outra.

Ainda segundo Gerhardt et al. (2009), a pesquisa qualitativa busca a compreensão e explicação referente ao pesquisado, como um grupo social, uma organização e se caracteriza pela objetivação do fenômeno, observância, descrição, compreensão e explicação, etc.. Prodanov et al. (2013) ainda afirma que na pesquisa qualitativa o ambiente é uma fonte direta de dados, sendo que fazem parte da pesquisa descritiva. 
No que se refere à pesquisa quantitativa, Prodanov et al. (2013) argumenta que ela utiliza informações numéricas para facilitar a descrição do problema pesquisado, analisar as variáveis, compreender e classificar os processos, sendo empregada em pesquisas descritivas. Além disso, este é um estudo caracterizado como de base populacional, visto que, objetiva analisar as características de uma doença que atinge a população de Porto Nacional (TO).

\section{Local de estudo}

O estudo foi realizado no município de Porto Nacional (TO), através de pesquisas sobre a o perfil epidemiológico da meningite no município, com ocorrência de 2010 a 2018. A cidade de Porto Nacional, está localizada no Estado do Tocantins e região Norte do Brasil, que segundo o Instituto de Pesquisa Econômica Aplicada - IPEA (2016), é uma das regiões do país com o menor Índice de Desenvolvimento Humano - IDH, ficando atrás somente da Região Nordeste. De acordo com o último censo realizado pelo IBGE, em 2010, a cidade de Porto Nacional (TO) possui 49.146 habitantes, porém com uma estimativa de 52.700 habitantes para a atualidade.

\section{Coleta de dados e variáveis}

Os dados referentes à Porto Nacional foram coletados em março de 2019, a partir de uma solicitação junto a Secretaria Municipal de Saúde de Porto Nacional (TO), que forneceu todos os dados referentes a incidência da meningite no município durante o período de 2014 a 2018. Realizou-se, também, uma coleta de dados referentes à incidência da meningite no Estado do Tocantins e no Brasil, para fazer uma discussão comparativa do município, estado e país. Estes foram coletados também em março de 2019 a partir do DATASUS, o portal de notificações do SINAN - Sistema de Informação de Agravos de Notificação. Os dados foram coletados a partir da divisão das seguintes variáveis: sexo, raça, faixa etária, incidência por mês, etiologia, identificação da meningite, evolução e classificação final.

\section{Análise de dados}

Para a análise dos dados, os principais instrumentos utilizados foram os programas Word e Excel do pacote Microsoft Office 2016, visto que por meio deles foi possível a organização dos dados através de gráficos (pizza e barras) e tabelas, que permitem uma melhor visualização dos resultados. Através dessas ferramentas, é possível analisar os dados estatisticamente, devido ao uso de dados e resultados numéricos, expressos em quantidade e porcentagem.

\section{RESULTADOS}

Para o período pesquisado, a meningite, em todas as suas formas, teve um total de 32 casos suspeitos, divididos por ano e sexo, conforme a figura 1. Houve um total de 3 casos em 2014, 7 em 2015, 6 em 2016, 4 em 2017 e 12 em 2018. O maior número é em 2018, e é preocupante por se tratar de uma doença com imunização, e apesar da medicina avançar ao longo dos anos, principalmente devido às tecnologias, 
ainda há aumento de casos dessa doença. Na maioria dos anos a incidência foi maior para o sexo masculino, com um total de 17 casos ou 53,12\%. Em relação à raça dos pacientes vítimas de meningite, para todo o período pesquisa não houve nenhuma notificação para as raças preta, amarela e indígena, somente branca e parda, sendo que há uma predominância muito grande para a raça parda, conforme a figura 2.

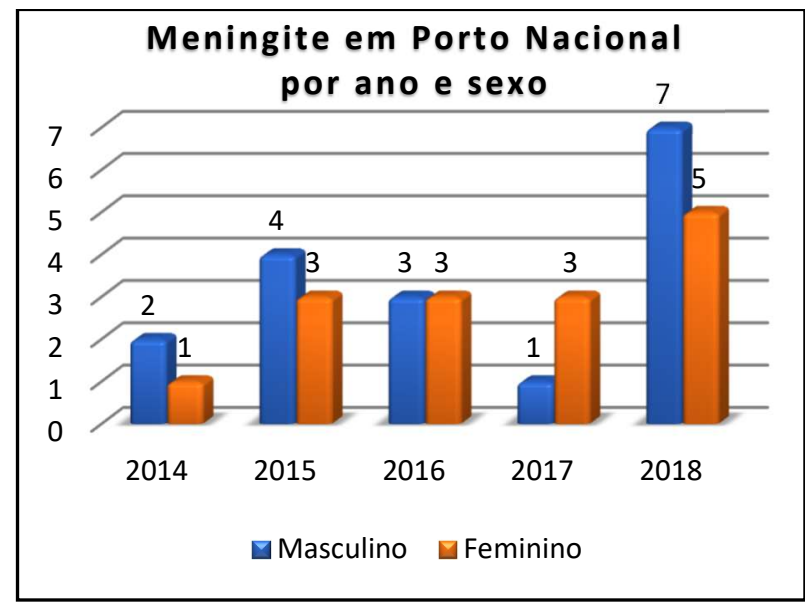

Figura 1: Incidência da meningite em Porto Nacional por ano e sexo.

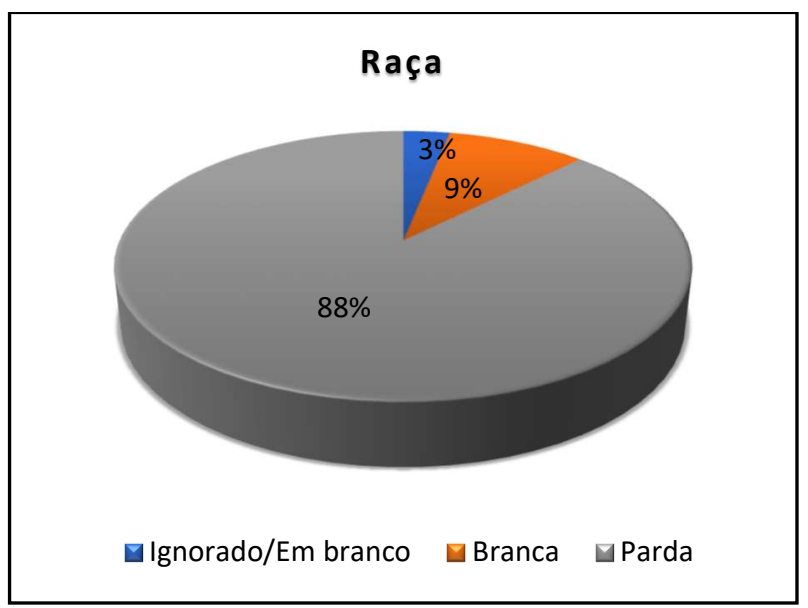

Figura 2: Raça das vítimas de meningite em Porto Nacional (TO).

No que diz respeito à idade das vítimas de meningite, os dados foram fornecidos por idade detalhada, de 0 a 80 anos, entretanto cada idade houve poucas notificações, algumas não tiveram nenhuma notificação. As crianças menores de um ano foram as maiores vítimas da meningite no período de 2014 a 2018. Houve 6 notificações para essa idade, enquanto as outras idades tiveram no máximo 3 notificações. Ao separar as notificações de idade por faixa etária, têm-se a figura 3, e conforme a tabela 1, em todo o período pesquisado, a meningite foi incidente em meses diversificados.

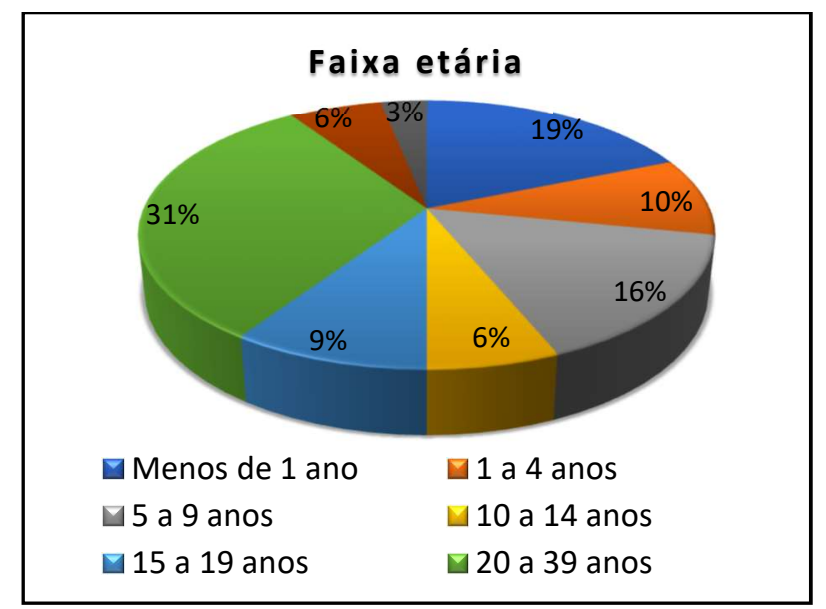

Figura 3: Incidência da meningite por faixa etária em Porto Nacional.

Tabela 1: Incidência da meningite por meses e ano.

\begin{tabular}{|l|c|c|c|c|c|c|}
\hline MESES/ANOS & $\mathbf{2 0 1 4}$ & $\mathbf{2 0 1 5}$ & $\mathbf{2 0 1 6}$ & $\mathbf{2 0 1 7}$ & $\mathbf{2 0 1 8}$ & TOTAL \\
\hline Janeiro & - & - & - & - & 1 & 1 \\
\hline Fevereiro & - & 1 & - & - & 1 & 2 \\
\hline Março & 1 & - & - & 1 & - & 2 \\
\hline Abril & - & - & 3 & - & - & 3 \\
\hline Maio & - & 1 & - & - & 1 & 2 \\
\hline Junho & 1 & 2 & 1 & - & 2 & 6 \\
\hline Julho & - & 1 & - & 1 & 1 & 3 \\
\hline Agosto & - & - & 1 & - & 3 & 4 \\
\hline Setembro & 1 & - & - & - & & 1 \\
\hline
\end{tabular}




\begin{tabular}{|l|l|l|l|l|l|}
\hline Outubro & - & 1 & - & - & 1 \\
\hline Novembro & - & - & - & - & - \\
\hline Dezembro & - & 1 & 1 & 2 & 0 \\
\hline
\end{tabular}

Ao se analisar por ano, percebe-se que as maiores incidências por mês foram de 3 casos em abril de 2016 e 3 casos em agosto de 2017, porém esses casos são isolados para esses anos, não se repetem nos outros anos do período analisado. Ao se comparar todo o período, o mês de junho é o que possui a maior notificação, com 11 casos no total, conforme a figura 4.

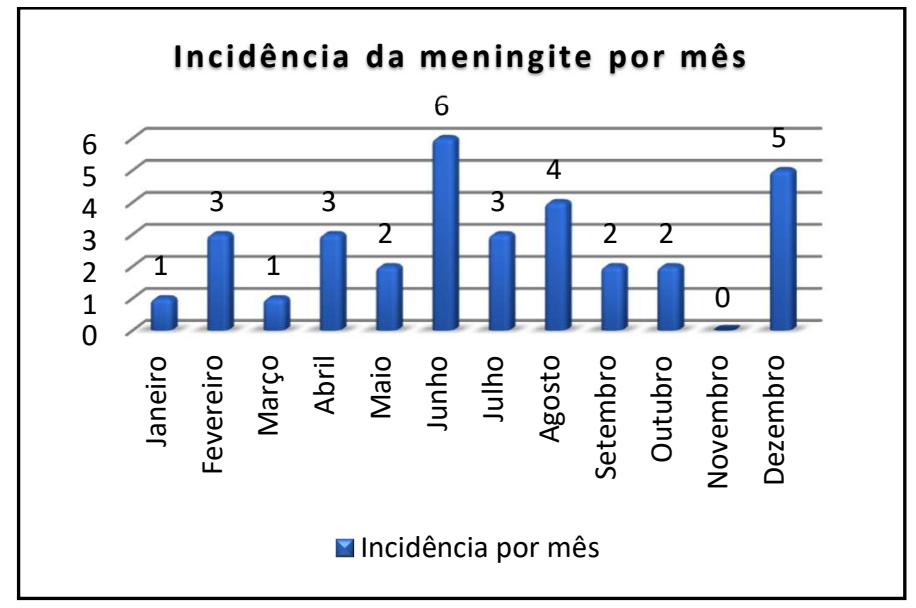

Figura 4: Incidência por mês da meningite em Porto Nacional (TO).

No Estado do Tocantins, o mês de maior incidência foi fevereiro, com 41 casos, enquanto o de menor incidência foi dezembro. Os casos de meningite notificados no município são divididos conforme a etiologia, sendo elas: Meningite Meningocócica (MM), Meningite Bacteriana (MB), Meningite Viral (MV), Meningite Pneumocócica (MP), e ainda há a Meningite Não Especificada (MNE), e Meningite de Outra Etiologia (MOE). Apesar disso, a maioria dos casos a etiologia foi ignorada ou não preenchida, e as outras etiologias foram bem divididas por ano, não havendo notificação para a meningite viral, conforme a tabela 2.

Tabela 2: Notificação de meningite por etiologia e ano em Porto Nacional (TO).

\begin{tabular}{|l|c|c|c|c|c|c|}
\hline ETIOLOGIA/ANO & $\mathbf{2 0 1 4}$ & $\mathbf{2 0 1 5}$ & $\mathbf{2 0 1 6}$ & $\mathbf{2 0 1 7}$ & $\mathbf{2 0 1 8}$ & TOTAL \\
\hline M. Meningocócica & - & - & - & 1 & 1 & 2 \\
\hline M. Bacteriana & - & 1 & - & - & - & 1 \\
\hline M. Viral & - & - & - & - & - & 0 \\
\hline M. Pneumocócica & - & - & - & - & 1 & 1 \\
\hline M. Não Especificada & - & 1 & 1 & - & - & 2 \\
\hline M. de Outra Etiologia & - & - & 2 & - & - & 2 \\
\hline Ignorado/Em branco & 3 & 5 & 3 & 3 & 10 & 24 \\
\hline
\end{tabular}

Para a confirmação dos casos suspeitos de meningite, na maioria dos casos utilizou-se a Punção Lombar. Para todo o período, em 24 dos 32 casos foi realizado a punção, em 6 casos não foi realizado e em 2 casos não há identificação. Através dos exames e testes de diagnósticos realizados, para todos foi identificado o aspecto líquor, e na grande maioria este foi detectado como límpido, um total de 18 casos, porém houve aspecto turvo e xantocrômico, conforme a figura 5. Após a realização de exames de diagnóstico, é possível obter a classificação final.

No período pesquisado, a grande maioria das 32 notificações de casos suspeitos de meningite foi descartada, segundo a figura 6 . Dos casos descartados, identificou-se que a maioria se refere aos casos do 
ano de 2018, visto que este foi o ano com o maior número de casos de meningite. Além disso, também se identificou que para o ano de 2014, todos os casos foram descartados, conforme a tabela 3. A partir da não confirmação dos casos de meningite, a grande maioria dos pacientes tiveram alta, porém também houve casos de óbito, conforme a figura 7. Sendo que, em 2014 e 2017 todos os pacientes com suspeita e/ou confirmação de meningite tiveram alta, conforme a tabela 4.

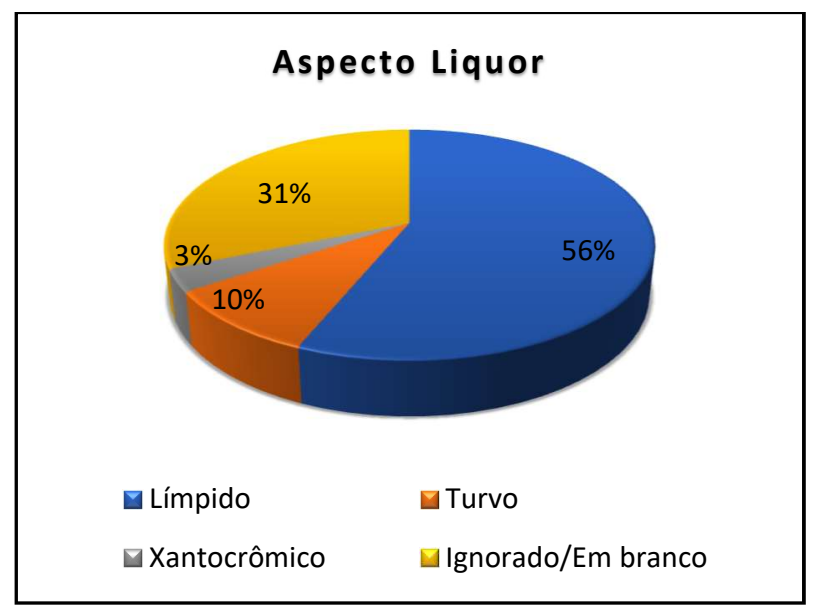

Figura 5: Aspecto Líquor para confirmação dos casos de meningite em Porto Nacional (TO).

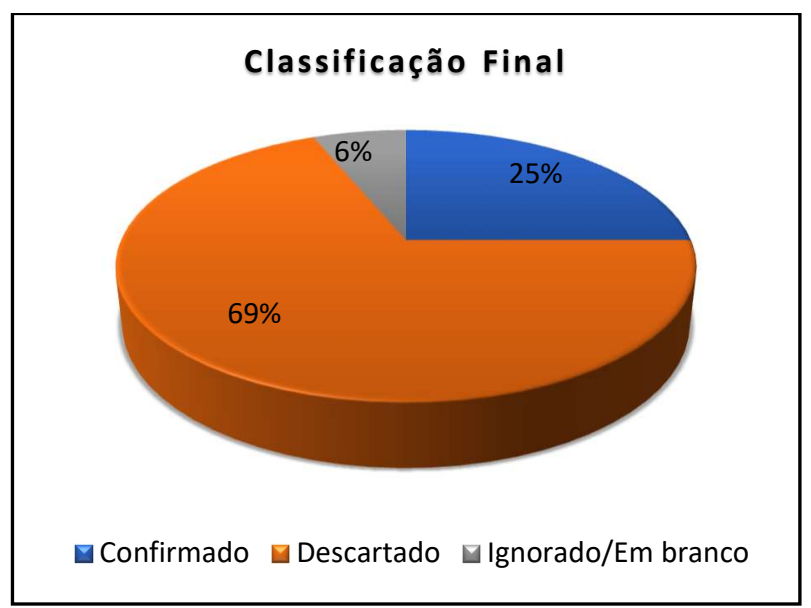

Figura 6: Classificação Final dos casos de meningite em Porto Nacional (TO).

Tabela 3: Classificação final da meningite por ano de notificação.

\begin{tabular}{|l|c|c|c|c|c|}
\hline CLASSIFICAÇÃO FINAL/ANO & $\mathbf{2 0 1 4}$ & $\mathbf{2 0 1 5}$ & $\mathbf{2 0 1 6}$ & $\mathbf{2 0 1 7}$ & $\mathbf{2 0 1 8}$ \\
\hline Confirmado & - & 2 & 3 & 1 & 2 \\
\hline Descartado & 3 & 5 & 3 & 3 & 8 \\
\hline Ignorado/Em branco & - & - & - & - & 2 \\
\hline
\end{tabular}

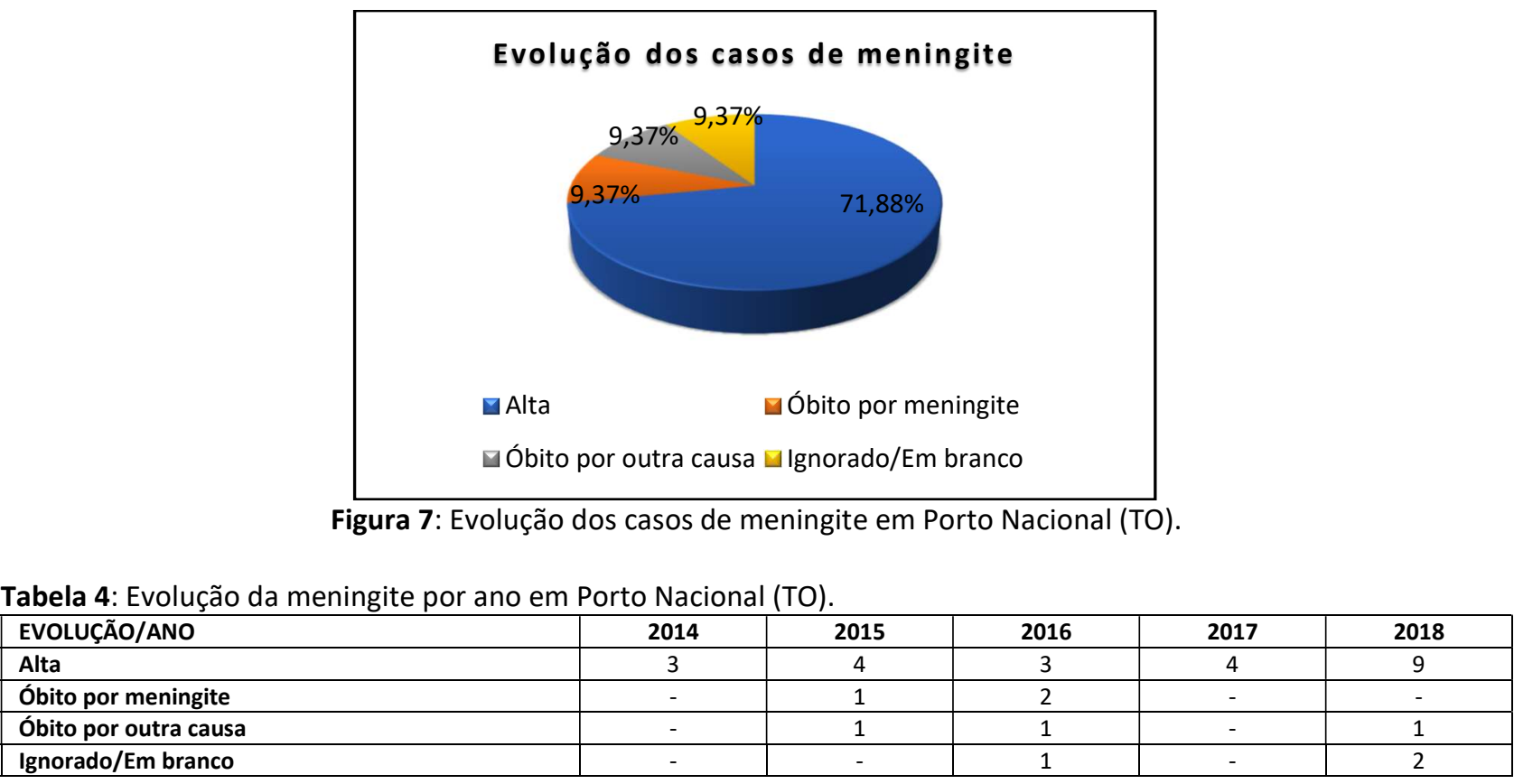

Tabela 4: Evolução da meningite por ano em Porto Nacional (TO).

\section{DISCUSSÃO}

Segundo Santos (2007), a meningite é uma doença que possui imunização, e que após a criação da vacina, os casos de meningite diminuíram consideravelmente. Por este motivo, ao analisar a incidência da doença em Porto Nacional (TO), percebe-se que não foi muito alta. Em um período de 5 anos, houve somente 32 casos suspeitos, sendo que por ano a incidência foi pouca, somente em 2018 que a incidência de casos 
suspeitos de meningite é preocupante, devido ter apresentado 12 notificações, bem superior aos anos anteriores, que tiveram no máximo 7 notificações. A preocupação se dá devido ao avanço das tecnologias para a medicina e imunização, desse modo o ideal seria que essa incidência diminuísse ao longo dos anos.

Porém, ao analisar a classificação final dos casos suspeitos, percebe-se que houveram somente 8 casos confirmados em todo o período pesquisado, sendo que no ano de 2014 nenhum caso foi confirmado, em contrapartida, em 2016 todos os casos foram confirmados, e no ano de 2018 que houve o maior número de notificações, somente 2 casos foram confirmados. Apesar disso, deve haver uma vigilância e constantes campanhas de imunização e conscientização para que a população se imunize.

Dos 32 casos notificados, a maioria se refere ao sexo masculino, entretanto é pouco superior à incidência no sexo feminino, pois trata-se de 53,12\%. Ao comparar essa incidência com o Estado do Tocantins, para o mesmo período pesquisado, de acordo com o DATASUS do SINAN, houve a notificação de 313 casos confirmados de meningite, sendo que destes, 192 casos (61,34\%) são do sexo masculino e 121 $(38,66 \%)$ casos para o sexo feminino. Devido os casos confirmados no município serem apenas 8 , percebese que Porto Nacional não teve casos significativos para o estado, o que indica um bom funcionamento da saúde pública do município em comparação com o Estado do Tocantins.

Essa maior incidência para o sexo masculino também é verificada nos dados nacionais, onde, de acordo com dados do DATASUS, de 2014 a 2018 houve 82.372 casos de meningite no Brasil, e, destes, 58,88\% se referem ao sexo masculino. Os dados são preocupantes, principalmente ao analisar que segundo o IBGE (2018), os homens vivem, em média, 6,9 anos a menos que as mulheres, e a meningite pode contribuir para isso, pois trata-se de uma doença que pode levar a óbito.

No que se refere à incidência por raça no município de Porto Nacional, a maior incidência se deu para a raça parda, com $88 \%$, e após para a raça branca, com $9 \%$, não havendo notificações para as raças preta, amarela e indígena. Ao comparar com os dados estaduais em nacionais, no Estado do Tocantins a raça parda também foi a mais prevalente, com cerca de $85 \%$, e em segundo lugar também ficou a branca, com quase $10 \%$, entretanto é diferente dos dados do Brasil, onde a raça de maior notificação é a branca, com $46,44 \%$ dos casos, enquanto que a parda ocupa o segundo lugar, com $29,4 \%$ dos casos.

A incidência por idade em Porto Nacional segue as definições da literatura, com maiores notificações para crianças menores de 1 ano, que, segundo Pobb (2013), é a idade mais atingida devido não terem o sistema imunológico amadurecido. Um dado preocupante referente à notificação por idade é para o ano de 2018, pois 3 das 6 notificações para crianças menores de 1 ano foi em 2018. Apesar da imunização e dos avanços com o passar dos anos, o ano de 2018 apresentou dados preocupantes, que evidenciam uma possível negligência na imunização das crianças, seja por parte dos pais/responsáveis, seja por parte da saúde pública.

Ao analisar por faixa etária, a faixa com o maior número de notificações foi a de 20 a 39 anos, contrariando a literatura, que, segundo Santos (2007), as crianças menores de 5 anos são as mais atingidas. Mas a análise da faixa etária não desqualifica por idade, onde em todo o período, houve 6 notificações somente para crianças de menos de 1 ano, enquanto outras idades tiveram no máximo 3 notificações. 
Referente ao estado do Tocantins, a meningite por faixa etária foi mais prevalente em crianças de 1 a 4 anos, com 18,21\% dos casos. O segundo lugar se refere às crianças menores de 1 ano, com 17,57\% dos casos. Para o Brasil, a faixa etária mais atingida foi a de 20 a 39 anos, semelhante ao município de Porto Nacional. Porém, os dados nacionais e estaduais não foram obtidos por idade detalhada, desse modo não dá para dizer qual a idade mais atingida.

No que se refere às notificações por mês, a análise é importante porque, segundo Stocco et al. (2010), os meses refletem os elementos climáticos, que possuem uma grande influência na manifestação da meningite, onde esta, apesar de ter ocorrências em qualquer época do ano, é mais comum as bacterianas serem mais incidentes no inverno, enquanto que as assépticas são não incidentes no verão.

Observou-se que o município apresentou um maior número de notificações no mês de junho, com 34,37\% dos casos. Segundo Silva Júnior (2016), o mês de junho compreende um período de inverno no Tocantins, bem como em Porto Nacional (TO), e se caracteriza por ser um dos três meses mais secos do ano. Já no Estado do Tocantins, o mês de maior incidência para o período pesquisado foi fevereiro, com 13,1\% dos casos. Diferente do município de Porto Nacional. Enquanto para o Brasil, o mês mais prevalente foi outubro, com $9,38 \%$ dos casos.

Os dados sobre a maior incidência em junho, no período de inverno, refletem a possibilidade de haver maior prevalência das meningites bacterianas, e isso é confirmado ao analisar as etiologias notificadas no município. Na maioria das notificações a etiologia foi ignorada ou em branco, com 24 casos, isso pode ter se dado devido haver 22 casos em que a meningite foi descartada e 2 casos em que foi ignorado se a meningite foi confirmada ou não.

Para o restante dos casos, as maiores notificações são o somatório das etiologias Meningite Bacteriana e Meningite Meningocócica, que são causadas por bactérias, com 3 casos dos 8 confirmados. É um dado preocupante, pois segundo Stocco et al. (2010), a meningite bacteriana é o tipo mais grave, e a principal responsável por complicações tardias, como sequelas neurológicas, além de poder levar a vítima a óbito.

Para o Estado do Tocantins, a etiologia de maior incidência foi Meningite Viral, com 40,57\% dos casos, assim como os dados nacionais, onde, no Brasil a maior incidência para o período pesquisado também foi a Meningite Viral, com $47,24 \%$ dos casos. Esses dados estaduais e nacionais diferem-se dos dados municipais. E isso evidencia ainda mais a preocupação referente ao município, pois ele não notificou nenhum caso de Meningite Viral, e a maior incidência é dos tipos de meningite mais graves, fazendo com que o município esteja mais em alerta.

Para a identificação e confirmação dos casos de meningite, Silva et al. (2018) afirma que a análise do aspecto líquor é necessária. Desse modo, em Porto Nacional (TO) essa análise foi realizada, e em 18 casos foi identificado que o aspecto é considerado límpido, o que descarta a meningite. A partir disso, verificou-se que $69 \%$ dos casos notificados de meningite foram descartados. Além disso, 71,88\% dos pacientes tiveram alta, e houve 3 casos de morte por meningite no município, sendo que estas foram nos anos de 2015 e 2016, e 
apesar do ano de 2018 ter tido preocupante e com maiores notificações, não houve nenhum óbito por meningite, o que demonstra a melhora da saúde pública com o passar dos anos.

Em contrapartida, a quantidade de óbitos por meningite é muito significativa a nível estadual, pois para o período pesquisado, o estado notificou 27 óbitos por meningite. Desse modo, a cidade de Porto Nacional (TO) representa $11,11 \%$ dos óbitos do Estado do Tocantins, um valor consideravelmente alto, pois segundo o IBGE, o estado possui 139 municípios. Portanto há uma alta concentração de óbitos somente em Porto Nacional.

Um dado que se destaca a partir dos fornecidos pela Secretaria Municipal de Saúde de Porto Nacional é que 26 dos 32 casos foram notificados no Bairro/Distrito de Pinheirópolis, que é um pouco afastado da cidade de Porto Nacional, e possui uma população mais carente, com menos acesso aos direitos básicos, como saúde e educação de qualidade. Isso pode explicar a maior prevalência da meningite na fase pediátrica, e na faixa etária de 20 a 39 anos, pois pode ser que haja uma negligência na imunização destes, devido à dificuldade dos moradores de Pinheirópolis em ter acesso à saúde. De um modo geral, os aspectos epidemiológicos da meningite em Porto Nacional, a partir da maior incidência, estão descritos na tabela 5.

Tabela 5: Aspectos Epidemiológicos da Meningite em Porto Nacional (TO).

\begin{tabular}{|l|c|}
\hline VARIÁVEIS & RESULTADO \\
\hline Sexo & Masculino \\
\hline Raça & Parda \\
\hline Idade & $>1$ ano \\
\hline Mês & Junho \\
\hline Etiologia & Meningite Meningocócica + Bacteriana \\
\hline Casos Confirmados & 8 \\
\hline Óbito por meningite & 3 \\
\hline
\end{tabular}

\section{CONCLUSÕES}

Apesar de um número pouco considerável de notificações de meningite no município de Porto Nacional (TO), não houve muitos casos confirmados, e destes, 62,5\% tiveram alta, o que evidencia que não há uma epidemia da doença no município e que apesar das notificações, a saúde pública tem oferecido tratamento eficiente para a doença. Porém, há muito o que melhorar, visto que ainda houve casos de óbito por meningite, e estes tiveram grande representatividade no Estado do Tocantins.

O ano de 2018 se mostrou preocupante, devido se apresentar como o ano de maiores notificações, e apesar da grande maioria ter sido descartada a meningite, houve 3 casos da doença em crianças menores de 3 anos. Percebe-se que deve haver mais campanhas de vacinação e conscientização para vacinação no município, para que não haja crescimento da meningite em 2019.

Ao comparar com os dados nacionais e estaduais, o município possui aspectos epidemiológicos bastante semelhantes, porém há uma diferenciação na etiologia que no município há uma maior prevalência para as meningites causadas por bactérias, enquanto no Tocantins e Brasil as causadas por vírus são as principais. É um dado preocupante para o município, pois esta é a forma mais grave da meningite. Medidas preventivas devem ser tomadas para que a meningite tenha ainda menos incidência em Porto Nacional, principalmente a meningite bacteriana. 


\section{REFERÊNCIAS}

BRASIL. Ministério da Saúde. Guia de Vigilância em Saúde. Brasília: MS, 2017.

CORDEIRO, A. P.. Pesquisa de biomarcadores e alvos terapêuticos para as meningites por meio da proteômica comparativa do líquor de pacientes. Belo Horizonte: 2013.

FERNANDES, B. R.. Diagnóstico diferencial das meningites. Revista Médica de Minas Gerais, v.18, n.3 2008.

GERHARDT, T. E.; SILVEIRA, D. T.. Métodos de pesquisa. Porto Alegre: UFRGS, 2009.

GIL, A. C.. Métodos e Técnicas de Pesquisa Social. 6 ed. São Paulo: Atlas, 2008.

GUIMARÃES, D. O.; MOMESSO, L. S.; PUPO, M. T.. Antibióticos: importância terapêutica e perspectivas para a descoberta e desenvolvimento de novos agentes. Química Nova, v.33, n.3, p.667-679, 2010.

IBGE. Instituto Brasileiro de Geografia e Estatística. Em 2017 expectativa de vida era de $\mathbf{7 6}$ anos. Rio de Janeiro: IBGE, 2018.
PEREIRA, D. N.. Meningites Bacteriana. Porto: Universidade Fernando Pessoa, 2014.

POBB, K.. Aspectos epidemiológicos e influência de variáveis climáticas nos casos notificados de meningite em crianças no município de Ponta Grossa-PR: 2002-2011. Revista Brasileira de Climatologia, v.13, n.9, p.202-213, 2013.

PRODANOV, C. C.; FREITAS, E. C.. Metodologia do trabalho científico: métodos e técnicas da pesquisa e do trabalho científico. Novo Hamburgo: Universidade Feevale, 2013.

SANTOS, A. V.. Meningites. São Paulo: CUFMU, 2007.

SILVA JÚNIOR, J. L. C.. Relato Técnico-Científico. Palmas: Unitins, 2016.

SILVA, H. C. G.; MEZAROBBA, N.. Meningite no Brasil em 2015: o panorama da atualidade. Arquivos Catarinenses de Medicina, v.47, n.1 2018.

STOCCO, C.. Influência de variáveis climáticas sobre a incidência de meningite e sua distribuição espacial no município de Ponta Grossa-PR: 2001-2005. São Paulo: 2010.

A CBPC - Companhia Brasileira de Produção Científica (CNPJ: 11.221.422/0001-03) detém os direitos materiais desta publicação. Os direitos referem-se à publicação do trabalho em qualquer parte do mundo, incluindo os direitos às renovações, expansões e disseminações da contribuição, bem como outros direitos subsidiários. Todos os trabalhos publicados eletronicamente poderão posteriormente ser publicados em coletâneas impressas sob coordenação da Sustenere Publishing, da Companhia Brasileira de Produção Científica e seus parceiros autorizados. Os (as) autores (as) preservam os direitos autorais, mas não têm permissão para a publicação da contribuição em outro meio, impresso ou digital, em português ou em tradução. 